\title{
Analogical reasoning in architecture
}

\author{
Sara Raed Majeed ${ }^{a}$ and Basim Hasan Al-Majidi ${ }^{a}$
}

${ }^{a}$ Department of Architecture, University of Technology, Iraq, Baghdad.

\section{ARTICLE INFO}

\section{Article history:}

Received 27 March 2019

Received in revised form 19 April 2019

Accepted 06 May 2019

Keywords:

Analogyical reasoning

Analogy

form

function

\begin{abstract}
A B S T R A C T
The concept of Analogy varies with the number of basic inputs and the difference in the influence of the basic inputs affecting their composition. In its general concept, architecture has two aspects related to the nature of the formation of analogue thinking: the first is its physical entity, which reflects the visual and visual values and the connection to the formal aspect, and the conceptual one related to the intellectual aspect and the nature of its composition, Through the mutual influence between the reality of the external entity and the nature of the ideas that man tries to reach, the research attempts to explore the concept of one of the necessities of the doctrines and the architectural movements in the production of architecture represented by analogue thinking The problem of research is based on [the need for a clear and specific knowledge in the definition of the concept of analogue thinking as a design strategy and mechanisms for the production of modulation according to analogue thinking at the level of form, structure and function in the products of global architecture] Solving the research problem by selecting a set of global samples. In this research, it is assumed that analogue thinking is an integral part of the analogy as a strategy and that to achieve analogue thinking, the products must be content within the reference, A number of different global samples with different time periods have been designed to be based on the strategy of analogue thinking, the variation in the construction period and the variation in their design characteristics in terms of Formal, functional and structural. This diversity and diversity of material production in the process of tracing the purpose of the research in particular. In addition, from which these samples can be applied to apply the concepts derived from the theoretical framework to achieve the hypothesis of research. The research aims at building a comprehensive framework for the analogy strategy and revealing its role in the formation of the architectural products, crystallizing a measurement tool for the analogy achieved as a method of thinking and its impact on the continuity of the architectural products and applying it to the architecture to be the reference of evaluation of architectural projects, whether in competitions or the academic field. That analogue thinking depends on the transition of mind by incorporating more than one idea to form the creative product achieved in reality, indicating the difference in the work of the analogy from the other creative channels where analogue play plays a role in the creation and the bringing of unusual ideas, approach to creative design and that man deals with architecture intellectually before the process of production is configurable.
\end{abstract}

(C) 2019 University of Al-Qadisiyah. All rights reserved.

\section{Introduction}

Humans tries to achieve the goals of conscious thinking by reflecting on everything he has produced throughout his history on Earth. We can return each product to the idea. Analogy thinking through analogies, metaphors and metaphors is profound in terms of qualitative values rather than quantitative ones. Which allows for the establishment of creative relationships between the present and the past. The characteristics used to

* Corresponding author. Tel.: +964(0)7702060626.

E-mail address: Sararaedmajeed43@gmail.com(Sara) 
redefine reality rather than simply decorating the language, but to provide a real transition to architecture, although not directly as a building tool, is a good tool for analysis and investigation in particular. The research problem was "the need for a clear and specific knowledge in the definition of Analogyical reasoning as a design strategy and mechanisms for the production of modulation according to Analogyical reasoning at the level of form, structure and function in the products of global architecture." The research aim was to build a theoretical framework for the strategy of Analogyical reasoning and detection Its role in the continuity of the thought of architectural products, and the development of a measuring tool for the analogy achieved as a way of thinking and its impact on the formation of architectural products and applied to the architecture to be a reference in the evaluation of architectural projects, whether in competitions or the academic field, The research took descriptive analytical approach in the construction of a theoretical framework that can be adopted as an analytical system to study and extrapolate Analogyical reasoning through four parts. The first part deals with the concept of analogy exposed. The most important theories and opinions behind the production, which reflect the different motives and reasons involved in the composition, the second part aims to complete the analytical system in the exploration of the intellectual thinking of multiple meanings and what term in the midst of the composition of the previous intellectual process of the process of physical reality production, which concluded research in identified based on different architectural propositions in fact the theoretical and practical, including the access to the third part, which is the research design and then the fourth part application results and conclusions and recommendations.

\section{Conceptual Framework of the Concept of Analogy}

In order to identify the most important definitions of the concept of analogy and connections, will be in this part to clarify the concept of analogy conceptual framework includes the contents of the Arabic and foreign dictionaries and then the definition of conventional analogy to the analogy architecture.

\subsection{The Linguistic and Normative Connotation of The Analogy}

The concept of Analogy came in several pictures according to the dictionaries and sources that touched on the concept in an analogy way: the name of the verb is analogy to the same: an analogy actor is analogy ]11,p40[ Ibn Mandur says: "This is like him and like him, as it is narrated and likened. Ibn Bari said: As for the analogy, it is only in those who agree ... The analogy is analogy to saying, "[2, p. 12], the analogy between features such as two things, which can be based on any comparison and is a form of thinking which implies one thing to be analogy to another in a certain respect, based on the analogy known between Things in Other Sides [Cambridge1972, p220] From the above it is noted that the concept of analogy refers to the analogy and equality between the features of two things compared to the properties that are used to explain the principle or idea, also known as: "the process of replacing the voice of another voice under the influence of a third voice close to him in the word or sentence, And can be expanded to include the interaction of two consecutive voices resulting in one voice different from them "[19, p217] It is also known as "adaptive adaptations of sound while adjacent to other sounds", and Ahmed Mukhtar Omar said: "Converting phonemes are either identical or partially identical." The symmetry or symmetry is the union of two things in a species, They are identical, but they do not share a analogy understanding, ]4, p. 26] Aristotle considered in his book "Public Speaking that the goal of the analogy is persuasion, that is, a rhetorical technique that makes speech acceptable in the mind of the recipient, that is, the presence of a dialogue between a sender and a future seeking to Create the mind of the latter so that it is able to act [28, p3]. Analogy is a central concept in human perception and creative thinking [27, p22 / 24]. They refer to clear relationships between theoretical logic, cognitive processes, long-term memory recall, classification and relationships between analogy and analogy. For example, [17, p34] is displayed on the coordinate design area where the axes are: "common relationships" and "attributes" [22, p12[ The analogy of the spatial domain of metaphor and metaphor is as follows: "Analogy elements and structural and structural analogy, while metaphors extend the spectrum of relational analogy at one end, and the analogy appearance on the other" Theoretical logic, cognitive processes and memory retrieval are the result of structural and structural relationships and common characteristics in order to diversify and enrich semantic and persuasive levels through the centrality of cognition and creative thinking.

\subsubsection{Types of Analogy:}

The idea of analogy in the creation and progress of science, whether through induction or extrapolation, contributed to the formation of general laws resulting from the recognition of symmetry in relations between successive objects. Analogy applications are widely used in the theory of analogy and are used in analogy synthesis. The qualities required. Dr. Taha Abdulrahman summed it up in four categories: The totality analogy between the two: the two things that share all the attributes: what is required of them, and what is permissible and what is impossible. Partial analogy: It establishes between the two things which share the same characteristics, so that one thing has the same characteristics as another, and another recipe for the departure of the other, [the principle of participation in certain qualities without limitation.] The general self-analogy: is established between the two ideals, ie, the two things that share the subjective [or psychological] characteristics without the occasional (or moral) qualities. According to Taha Abdul Rahman 4, the speakers come out of the selfattributes that are based on the analogy, what they call the [characteristics of the public] such as occurrence and presence and the ground, because such qualities may be shared by differentiated.

Self-analogy: It is established between the two extremes, that is, between the two things that share the most characteristic characteristics. These characteristics necessitate the identification of the relations between them, with their order, making some more general, some middle, some more specific.

The most important characteristics are those that bind all qualities and are not binding on others, and the middle is the one that binds others and is required of others. The most common ones are those that are binding on others and are not necessary from others. [14, p. 15-47], prudent is the most powerful source of creative ideas in architectural design. And distinguished three analogy categories: the morphological-visual-structural-philosophical analogy, together with Philippe Steadman 2008, which identified two distinct types of interpretation on the two analogy: visual [appearance composition] First to [directly analogy] [mirror] and indirectly indirect [placing the object in place] [38, p201.]

\subsection{Thinking and Analogy:}

Thinking is one of the most difficult processes in which the human mind has to understand and thus define. The reason why man's thought in many of the physical and vital processes around him is trying to understand some 
of them and still tries to understand others. In these cases he thinks of something outside of him When you are at the top of a mountain, knowing who is at the bottom of the mountain is better than knowing you and your ability to gather more information about it, Trying to understand the thinking process employs the thinking tool to understand itself and to understand what it needs to look at from outside or above it [13, p. 2], the intellectual source is the process of higher biological directed in the brain, shared by the implementation of the brain thinking tool Which deals with some of the stored and received by the moment of thinking of information and experiences, convictions and trends, and participate in the implementation of nerve impulses and electrical currents, the treatment is in a kind of lower processes such as comparison, contrast, analysis, synthesis, classification and arrangement and express the human feelings in body language has Is expressed by a word, a book, or a sermon, and may turn into behavior that is opposed to systematic or planned behavior aimed at reaching the result that led to the process of thinking.

Thinking is the source of every human act. It is an expression of a living experience, a language that enables the expression of emotions and selfconsciousness. It does not matter if it is joyful, sad, tender or direct, thin or violent, romantic or funny. To convey something to others is to express a living experience, in terms of its ability to explore its paradoxes and dilemmas, feeding it back to experience, to example, to question and to think, if we find a new role to think about what is the engine of philosophical consideration [12, p. 28] , The concept of analogy and Analogyical reasoning builds a bridge between unfamiliar concepts and earlier information for learners to help them create a new knowledge structure specific to abstract concepts. Any problem that seems strange and unfamiliar can be understood if it is thought through analogy and representation. Helps to explain the highly abstract relationships such as the atom and the solar system. It also facilitates learning by building relationships between the interactions. Thus, the interactions are an effective tool in facilitating the process of building the knowledge of the individual on the basis of concepts that Flag and previous knowledge available.

\section{The Concept of Analogyical Reasoning :}

The term symmetry is used to illustrate a particular idea, problem, or solution by finding an example of a common problem in order to arrive at a suggested qualitative description of the problem of these interrelated ideas. This helps to test the problem more clearly by identifying analogy elements among analogy models through which Access to a new style of solution. Abdalmutallab shows that $80 \%$ of the innovative ideas originated in Analogyical reasoning. The writers borrow their ideas from life, events, television, advertisements, children and headings, as we see in mechanical systems [10, p. 10] Reference to the source is the objective of the analogy, and Analogyical reasoning generally assumes that if two states or objects are known to be identical in some respects, they are likely to be identical to each other. The Analogyical reasoning between the terms is based on an understanding of these terms, The relationship between terms together and Analogyical reasoning is a reflection of two entities [source, rule and objective] by comparing them by finding analogy and dealing with one goal in relation to the way they deal with another source [source or base] [18, p13], Baker stated that the problems can be solved by three systems: inductive, inductive, and Analogy reasoning; Analogyical reasoning is one of the strategies used in problem solving where it takes a solution from the source and transfers it to the target [problem] using analogy may be a strategy or context by connecting the familiar to Uncommon [new problem]
[16, p70], It is observed that Analogyical reasoning is to think of two entities to arrive at a suggested qualitative description of these ideas that are connected to the production of innovative ideas and to find aspects of symmetry and dealing with the goal where problems can be solved by Analogy systems of Analogyical reasoning

\subsection{Analogy Sources of Analogyical reasoning:}

The architectural designer and critic is concerned both with the ideas and the architectural forms designed, as the architectural forms are different from each other in the extent to which they are achieved for certain purposes, which is a standard for the period in which this effect was born or that, These standards are crystallized and determined by the theory of architecture, Some of them considered the [good] architectural form to express their assigned function, and many forms were characterized at the beginning of the twentieth century according to this criterion Some of them considered the architectural form as a text analogy to the language text that carries a coded message using previously known architectural elements and used in the writing of these texts. New architectural forms were also distinguished according to this criterion. Some of them focused on the potential of the building material in shaping its forms Architectural Formation Which: (Analogys: Which is based on the relationship between craft, Metaphors: Which is based on innovative relations between the two, Essences: Which are based on determining the origin of phenomena and the most fundamental aspects of functional needs, concepts Programmatic: Which is based on operational functional needs, ideals: Which depend on universe values]23,p223,253].

\subsection{Analogy Thinking and Design Process:}

The design process goes through the flow of information along with ideas but at different levels and design is a set of ideas and events and the architectural mind searches in memory to find elements and components that match the needs of the problem, And compensate for the lack of information through the various references, the designer can achieve a wide range of goals through the design idea, and different projects vary these objectives or change the value resulting from the achievement and hence show the levels of application of the architectural idea as follows:

- Function Level.

- The space level.

- Movement level.

- Level of formation.

- The level of relationship with the environment.

The talk of a classification of ideas may be difficult as the way of thinking and expressing it is clearly different from one person to another, but there is a link between each group of ideas that makes it a doctrine and direction analogy to it in its general framework and characteristics are driven to say that this idea follows him or not and here The relationship of analogy to thinking of three levels [formal, functional and structural] is evident at the level of architectural design. The types of architectural ideas may be classified as follows:

The planning idea: This idea is reflected in the overall planning of the project as a whole to appear in the buildings and coordination of the relationship and bonding of the blocks, usually in multi-building projects or projects that require open areas with specific spaces and this idea is a general idea mostly include type or more of the following ideas mentioned. Technical idea: This idea deals with the core of the design problem directly through its solution in a purely technical manner, and using the means of 
technology and innovations. It should be noted here that it can not be said that this idea is a design idea unless it affects the design directly, The goal is to design a product that solves a problem, not a problem for any design, but it is ultimately dry and expansive so it is also best to combine it with another kind of ideas to give it a soul.

The Philosophical Concept: The philosophical approach is one of the most powerful intellectual schools and has the ability to convey general concepts. At the same time, it may lead to disdain of the idea, especially when the philosophy becomes a novel with several chapters. The strength of this type of ideas is reinforced by the multiplicity of ideas and their links with the project and its components. It is also necessary to mention here the need to move away from the surface in the translation of the idea and the search for the dimensional dimensions of its contents [35, p30].

Inspirational idea: Each line of the lines gives a different impression in the brain and when combined together in a stereoscopic shape, a general suggestion is formed that translates into the brain in a certain way (happiness, hope, sadness, balance, disturbance, etc.). Aspects of the project to search for the desired inspiration and starting from the same project, where it analyzes the components of the project and express them in forms of relevance. It can be said here that this type of ideas is often used with another type, because it does not ensure the delivery of the side of inspiration in a uniform manner for all.

The symbolic idea: It is very analogy to the idea of inspiration, but does not depend on the meaning inspired by the line and the interpreter of the brain receptor, but depends on the link of the shape of the project through some of the usual symbols such as the food dish link to the restaurant, or bank paper bank and so on. In primary forms or lines should not reflect the basic form of the element but symbolize it.

Impressionist idea: It is a very superficial idea and a lot of criticism, and it can be said that it does not require a high amount of knowledge and does not need to develop where a project-related element is captured and falls on the project's current form as it is, It is not clear here that this type of thinking has failed.

abstract idea: Here the designer to quote a specific element and be of a symbolic or inspirational nature, but not only contrary to the design, but enters the process of abstraction to finally get a new form serves the distribution of blocks required according to the studies of the project, and the strength of this idea if the introduction The philosophical aspect of the process of abstraction itself.

Structural idea: The construction idea is often derived from the abstraction of a structure in nature, used to solve the problem of construction but in a unique way, it can be argued that this idea is a branch of the abstract idea [34, p2] show in Fig. 1.

\subsubsection{Analogy thinking and design construction:}

The architectural form is subject to many different elements and trends that control the process of its production. These elements can be classified as functional or structural dimensions. Some of them may also be included under the influence of psychological factors and values of society with conceptual dimensions related to the person's ideas and the nature of the influences, There are four major features in which the architectural form can be seen as presented by Ahu Gurler in a paper entitled "Domineering and Promise Patterns". These features are:

- Formal features.

- Functional features Functional aspects.

- Structural features.

- Psychosocial features(Socio-psychological aspects) [24, p99] .
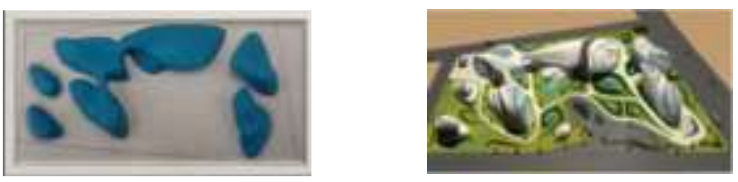

Technical idea

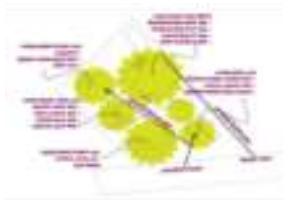

The planning idea

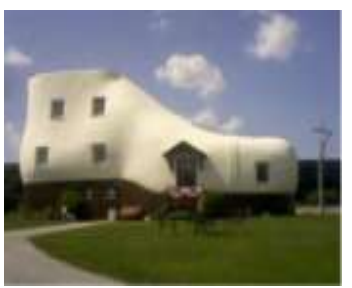

Impressionist idea



Abstract idea
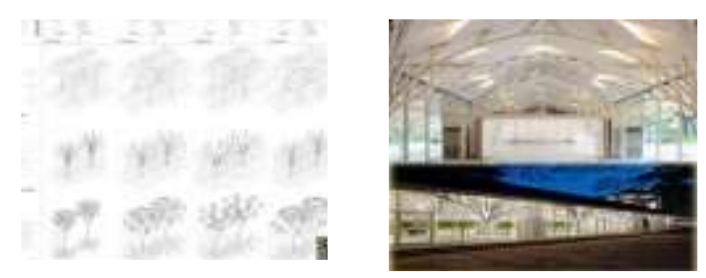

Structural idea
Analogy thinking and formal construction: The architectural form has elements that the product of architecture can deal with in order to understand the different production formula in order to avoid many of the negatives resulting from the exclusion of this intellectual stage from thinking. The form has two important characteristics. The first is to determine the design approach that architecture takes to achieve its products, By adding another function [expressive, symbolic, and semantic] to the products, in the case of the analogy of the noun in the determinants and function, the products from the source is more acceptable and performance than the products that achieves the function of protection only. It is clear that the main engine is the intellectual or conceptual dimension. The idea includes all that is related to mental activity and what includes the arrangement of things that lead to unknown as a tool for thinking [1, p. 55], 
or is the intellectual content and the sum of the ideas of the human mind as a whole takes its privacy from the contact with the cultural and social environment that we deal with. The way of thinking contributes to several facts that are part of reality [6, p. 12] The individual in his life $m$ Life itself as long as it is still alive and the human is only a series of series of ideas turn to human behavior, including the crystallization of human personality, through the crystallization of these ideas crystallize personality, the ideas rely on those generators that the mind when receiving an event where the event is crystallized In the unconscious to an idea in the subconscious until the emergence of a new idea or a certain event in the new appearance, and the human is only a set of ideas that control the behavior, and analytical psychology on the principle of practical analysis of psychological ideas and acquired in the psychological and traumatic event through which The $\mathrm{p} \mathrm{Z}$ that idea generated by psychological stress, the mind and heart can be synonymous in the sense of ideas and feelings is a mix between the heart and mind [13, p. 23].

Analogy thinking and functional construction: It is about functional purposes during the process of Analogyical reasoning, as it matches the suitability of animals and plants in their environment. It is linked to the performance of the Analogy process and its anatomical analogies related to the state of analogy in function but necessarily analogy in structure and anatomical position between different organisms and architecture. [42, p45] is in contrast to the symmetry that points to the analogies between organisms As structures and anatomy, structures that appear symmetry are called homogeneous structures may be analogy in structure and appearance but perform different functions. On the other hand, structures analogy to analogy structures and analogy structures and homogeneous structures of evolutionary origin are called anatomical analogies in which the anatomical structures [or behavioral qualities] exist between two objects not connected to the same functions and in Gothic architecture are clearly observed the use of analogy parts Of anatomical organisms, and of analogy kinds of environmental analogies examine the relationship between some organic body functions and image or form; and to show a analogy relationship apply between some functions of buildings, and their forms. These were somewhat general to the architectural functions, applicable to buildings of almost all kinds such as judging usable space, their relation to occupied site space retention or heat loss, and acceptance of daylight affecting the surface area of walls and ceiling. The forms of buildings correspond to each other [43, p7], and may be to express specific functions that may be related to the size, shapes and relative disposal of rooms, the placement of doors, windows, and playgrounds. With these Specialized uses include: theaters, railway stations, office buildings and at the same time [26, p54].

Analogy thinking and structural construction: These are positive and negative relationships: the positive is the presence of the meaning or the information of the thing and the negative is the meaning that is formed through the new relationships that are formed by any information added to it through its presence in the new context and relations And in the case of borrowing a certain form and design of the idea on the basis of that is referred to the forces of tension and pressure in the human body sometimes indicates that the depth of the analogy between the source and the objective, or the nature of symmetry taken in the process of emitter Of, the extent of the analogies related to the depth of the source and target [22, p23[, The production of the architectural form is done according to general and vague intellectual conditions that include the behavior of the Architect and what should be the architecture on the other hand. This process may be characterized by different concepts and different ideologies such as the spirit of the place or the spirit of the times or the higher Types and other concepts that do not represent themselves Clear things may differ in terms of understanding and application from time to time and from place to place according to the Architect understanding of the role of the cultural and social environment and his theoretical and intellectual commitment to life.

\section{Literature Review:}

After the previous were put forward concepts related to analogue thinking and analogy in several aspects will be in this axis to complete the launch of specialized studies for the purpose of using them with the previous axes in the design of the research will be clarified through the following scheme:

Table 1. Shows the previous studies and the most important vocabulary to which they were addressed

\begin{tabular}{|c|c|c|}
\hline Studying & What the study addressed & Object of the study \\
\hline $\begin{array}{l}\text { Rowe, P., G., } \\
1987\end{array}$ & $\begin{array}{l}\text { The study dealt with the process of the effectiveness of architectural design, with } \\
\text { a series of scenes or successive intellectual snapshots, and away from the doctrine } \\
\text { of correlative psychology, which adopts a method based on the interpretation of } \\
\text { the process of thinking about the associations between the concepts and the } \\
\text { behavioral doctrine that establishes a catalyst model, The study determines the } \\
\text { possibilities of the intellectual production of the designer through a process of } \\
\text { rotation that includes the evaluation and evaluation of the big idea. The study } \\
\text { focuses on the fact that the intellectual production mechanisms of the designer } \\
\text { often take the form of Readers and analogy }\end{array}$ & $\begin{array}{l}\text { Design is an effectiveness that depends on a } \\
\text { set of scenes related to the process of thinking }\end{array}$ \\
\hline $\begin{array}{l}\text { Ozgu Ozkan and } \\
\text { Fehmi Dogan, - } \\
2012\end{array}$ & $\begin{array}{l}\text { The study presents the differences of architectural products resulting from the } \\
\text { use of analogue thinking between the stylist and the expert. It consists of four } \\
\text { functions: examples of the source of the evaluation, selection of the source of the } \\
\text { field and design of a bus station. The results indicate significant differences } \\
\text { among the participants regarding the safety of classifications. The results showed } \\
\text { a significant relationship between the level of experience and selection of } \\
\text { participants from the source categories, the reasons cited for their selection, the } \\
\text { type of analogy that was created between the source and the objective and } \\
\text { concluded that experts prefer "mental jumps" while students prefer to copy } \\
\text { literally sources. Design Problem The results of the pilot study are reported to } \\
\text { have investigated whether students of different levels of architectural education } \\
\text { and expert architects differ from each other in the way they are used analogy to }\end{array}$ & $\begin{array}{l}\text { The difference between the use of analogue } \\
\text { thinking between the novice designer and the } \\
\text { expert based on knowledge and mental jumps } \\
\text { to produce analogies }\end{array}$ \\
\hline
\end{tabular}




\begin{tabular}{|c|c|c|}
\hline & $\begin{array}{l}\text { a particular design task and goals related to symmetry, Which arise between } \\
\text { sources and target ranges and compared with other analogy research }\end{array}$ & \\
\hline $\begin{array}{l}\text { An Inductive } \\
\text { Approach- } \\
\text { Hyunmin Cheong- } \\
2014\end{array}$ & $\begin{array}{l}\text { The study presents the correlation between analogy understanding or lack of } \\
\text { understanding and its relation to design by comparing the analogies between two } \\
\text { concepts. Extraction and transfer of knowledge from one concept to another } \\
\text { allows designers to develop design concepts that analogue reasoning plays a key } \\
\text { role in creative design, and then transfer analogy strategies to develop design } \\
\text { solutions. The research objective is to gain a better understanding of the process } \\
\text { of analogue thinking in nature-inspired biomimetic forms. The inductive } \\
\text { approach to the perception of analogue thinking behind biological design and the } \\
\text { description of the biological text have been used. Phenomena that contain causal } \\
\text { relationships are more likely to be useful for analogies of design problems. } \\
\text { Causal relationships often explain how functions are achieved by behaviors. She } \\
\text { focused on the analogies between two concepts and analogue reasoning through } \\
\text { simulated forms of nature and the use of an inductive approach to the perception } \\
\text { of analogue thinking behind dynamic design. Through creative thought, between } \\
\text { the functions of objects and take advantage of the system inherent in the bio- } \\
\text { design principle of growth and its use in architecture }\end{array}$ & $\begin{array}{l}\text { The relationship between analogy } \\
\text { understanding or misunderstanding and its } \\
\text { relation to design by comparing the analogies } \\
\text { between two concepts. Extraction and transfer } \\
\text { of knowledge from one concept to another }\end{array}$ \\
\hline $\begin{array}{l}\text { Mary Lou Maher- } \\
2015\end{array}$ & $\begin{array}{l}\text { This paper presents a methodology for identifying relevant design elements for } \\
\text { compiling new structural designs using previous design situations and } \\
\text { corresponding solutions. The study is a reflection of the observation that } \\
\text { engineers use relevant experience when solving new problems, the methodology } \\
\text { is the application of transformational analogy, a form of analogue thinking has } \\
\text { been developed a model system to implement the methodology, the utilization of } \\
\text { the expert knowledge-based system techniques. Where the experience and } \\
\text { knowledge of the designer as the resource faces a new design task, experience } \\
\text { that can only be accumulated over a long period of practice. This paper proposes } \\
\text { a methodology using previous design situations and solutions to plan the } \\
\text { installation of new designs. A popular way to use experience to solve new } \\
\text { problems is to develop an expert system that contains an appropriate } \\
\text { representation of relevant expertise in the form of inference that becomes the } \\
\text { basis of inspiration rules and refers to two analogy types of analogy } \\
\text { transformational derivational analogies and steps Thinking about building the } \\
\text { past The solutions can be retrieved and modified in order to build derivative paths } \\
\text { towards solutions to new problems. The transformative analogy concerns only } \\
\text { the definitions and solutions of the problem and ignores the thinking processes } \\
\text { that lead to these solutions in this The situation requires a new storage solution } \\
\text { to the problem in memory for later use }\end{array}$ & $\begin{array}{l}\text { The use of previous design cases and their } \\
\text { solutions for planning the installation of new } \\
\text { designs A popular way to use experience to } \\
\text { solve new problems is to develop an expert } \\
\text { system that contains an appropriate } \\
\text { representation of relevant expertise in the } \\
\text { form of inference which becomes the basis of } \\
\text { inspiration rules and touched on two analogy } \\
\text { types of transformative analogy } \\
\text { transformations and thought steps in building } \\
\text { the past Solutions can be retrieved }\end{array}$ \\
\hline Safo ,2008 & $\begin{array}{l}\text { The study examined the effect of analogies on the design process in the academic } \\
\text { milieu through a historical view indicating that man over the ages uses the } \\
\text { formative manipulations even implicitly in his artistic and architectural activity } \\
\text { for a motive that may be religious, symbolic or mental, and may be unconscious } \\
\text { [p. 7.2] The richest source for creating ideas in architecture has been used by } \\
\text { many architects at one time or another in their practical lives as well as the } \\
\text { psychological significance of the pleasure they receive [p. 9]. The study also } \\
\text { examines the importance of the designer's self-role in the process of creating the } \\
\text { architectural form to stimulate and generate ideas and derive architectural forms } \\
\text { from the other side [p. 14]. The analogy study deals with the design products of } \\
\text { the architectural study students as one of the important design strategies in the } \\
\text { architectural design process, Composition and Derivation [p. 10], where the } \\
\text { study dealt with the relationship between the designer and the analogy and } \\
\text { explain the causes and sources of analogy }\end{array}$ & $\begin{array}{l}\text { Design is likewise the richest source for } \\
\text { creating analogy ideas on the design process } \\
\text { in the academic milieu through a historical } \\
\text { view indicating that man over the ages uses } \\
\text { the formative manipulations }\end{array}$ \\
\hline Linsey-2014 & $\begin{array}{l}\text { The study examined the concept of analogy as the process of linking cases from } \\
\text { one domain to the other [objective] by establishing relationships or } \\
\text { representations of designs that share at least one function or behavior [p1]. The } \\
\text { study also focused on analogue correlation and retrieval of human cognition How } \\
\text { the problem occurs Where previous research has shown that multiple } \\
\text { representations facilitate logical reasoning by retrieving effective manipulations } \\
\text { and the novel stored in long-term designers' memory [p12], and many examples } \\
\text { of innovative systems and products based on analogy can be found in practice } \\
\text { Such as products inspired by nature and living organisms [p3]. This study has } \\
\text { shown methods and methods such as design, analogy techniques, and the need } \\
\text { for methods to understand creative cognition in innovation. The study also }\end{array}$ & $\begin{array}{l}\text { Analogy represents the process of linking } \\
\text { cases from one domain [source] to another } \\
\text { [goal] by establishing relationships or } \\
\text { representations of designs that share at least } \\
\text { one function or behavior }\end{array}$ \\
\hline
\end{tabular}


After looking at a range of architectural ideas and exploring the most important concepts and in-depth aspects that were put forward in the previous axes, the research reached the most important aspects of the concept which established the conceptual framework for the research

\begin{tabular}{|c|c|c|c|c|}
\hline key & secondary & \multicolumn{3}{|c|}{ possible indicntors } \\
\hline \multirow{26}{*}{$\begin{array}{l}\text { 1- } \\
\text { cmploymcnt } \\
\text { mecharisms } \\
\text { thinking } \\
\text { analogue }\end{array}$} & \multirow{23}{*}{$\begin{array}{l}1.1 \\
\text { intellectual } \\
\text { systems } \\
\text { [functional, } \\
\text { conceptual] }\end{array}$} & $\begin{array}{l}1,1,1 \text { system } \\
\text { of } \\
\text { integrating } \\
\text { and } \\
\text { matching } \\
\text { architectural } \\
\text { ideas }\end{array}$ & implicit funct & lal ideas \\
\hline & & \multirow{3}{*}{$\begin{array}{l}1.1 .2 \text { the idea } \\
\text { of bonowing } \\
\text { from the } \\
\text { intellectual } \\
\text { model }\end{array}$} & \multicolumn{2}{|c|}{$\begin{array}{l}\text { philossophical coaceptual } \\
\text { ideas }\end{array}$} \\
\hline & & & \multicolumn{2}{|c|}{ borrowing an opposite idea } \\
\hline & & & \multicolumn{2}{|c|}{ alsstraction of botrowed ides } \\
\hline & & $1.1,3$ analog & \multicolumn{2}{|c|}{ diversity of borrowed ideas } \\
\hline & & systcm & \multicolumn{2}{|l|}{ analog systcms } \\
\hline & & & \multicolumn{2}{|c|}{ conparative systems } \\
\hline & & 1.1 .4 & \multicolumn{2}{|c|}{ relational systems } \\
\hline & & & \multicolumn{2}{|c|}{ solve the problem } \\
\hline & & & \multicolumn{2}{|c|}{ explanation to others } \\
\hline & & 1.1 .5 & \multicolumn{2}{|c|}{ use visual imaginativa } \\
\hline & & $\begin{array}{l}\text { thought to } \\
\text { the same }\end{array}$ & \multicolumn{2}{|c|}{$\begin{array}{l}\text { expand the search for } \\
\text { similarities }\end{array}$} \\
\hline & & & \multicolumn{2}{|l|}{ visualization } \\
\hline & & & \multicolumn{2}{|c|}{ implicit analogy } \\
\hline & & & \multicolumn{2}{|l|}{ metaphor } \\
\hline & & & \multicolumn{2}{|c|}{$\begin{array}{l}\text { cncounfict and } \\
\text { synchironization }\end{array}$} \\
\hline & & & \multicolumn{2}{|c|}{ reduecd iniellectual events } \\
\hline & & & \multicolumn{2}{|c|}{ track, convent and merge } \\
\hline & & & \multicolumn{2}{|c|}{ reference formats } \\
\hline & & & \multicolumn{2}{|l|}{ recovery } \\
\hline & & & \multicolumn{2}{|c|}{ intellectual transportation } \\
\hline & & & \multirow{2}{*}{$\begin{array}{l}\text { vistal recall } \\
\text { cunsolidation }\end{array}$} & visual recall \\
\hline & & & & consobdaticen \\
\hline & \multirow{3}{*}{$\begin{array}{l}1.2 .2 \\
\text { Material } \\
\text { systems } \\
\text { [formal, } \\
\text { structural] }\end{array}$} & \multirow[t]{3}{*}{$\begin{array}{l}1.2 .1 \text { optical } \\
\text { similar } \\
\text { systcms }\end{array}$} & \multirow{3}{*}{$\begin{array}{l}\begin{array}{l}\text { integrated } \\
\text { integration }\end{array} \\
\text { partial } \\
\text { integration } \\
\text { comparative } \\
\text { analogy }\end{array}$} & $\begin{array}{l}\text { integrated } \\
\text { integration }\end{array}$ \\
\hline & & & & $\begin{array}{l}\text { partial } \\
\text { inlegration }\end{array}$ \\
\hline & & & & $\begin{array}{l}\text { comparative } \\
\text { analogy }\end{array}$ \\
\hline
\end{tabular}

problem. A group of vocabulary, the mechanisms of employing analogue thinking: [mechanisms of functional and conceptual intellectual systems, mechanisms of formal and structural physical systems] and as in Table 2. include:

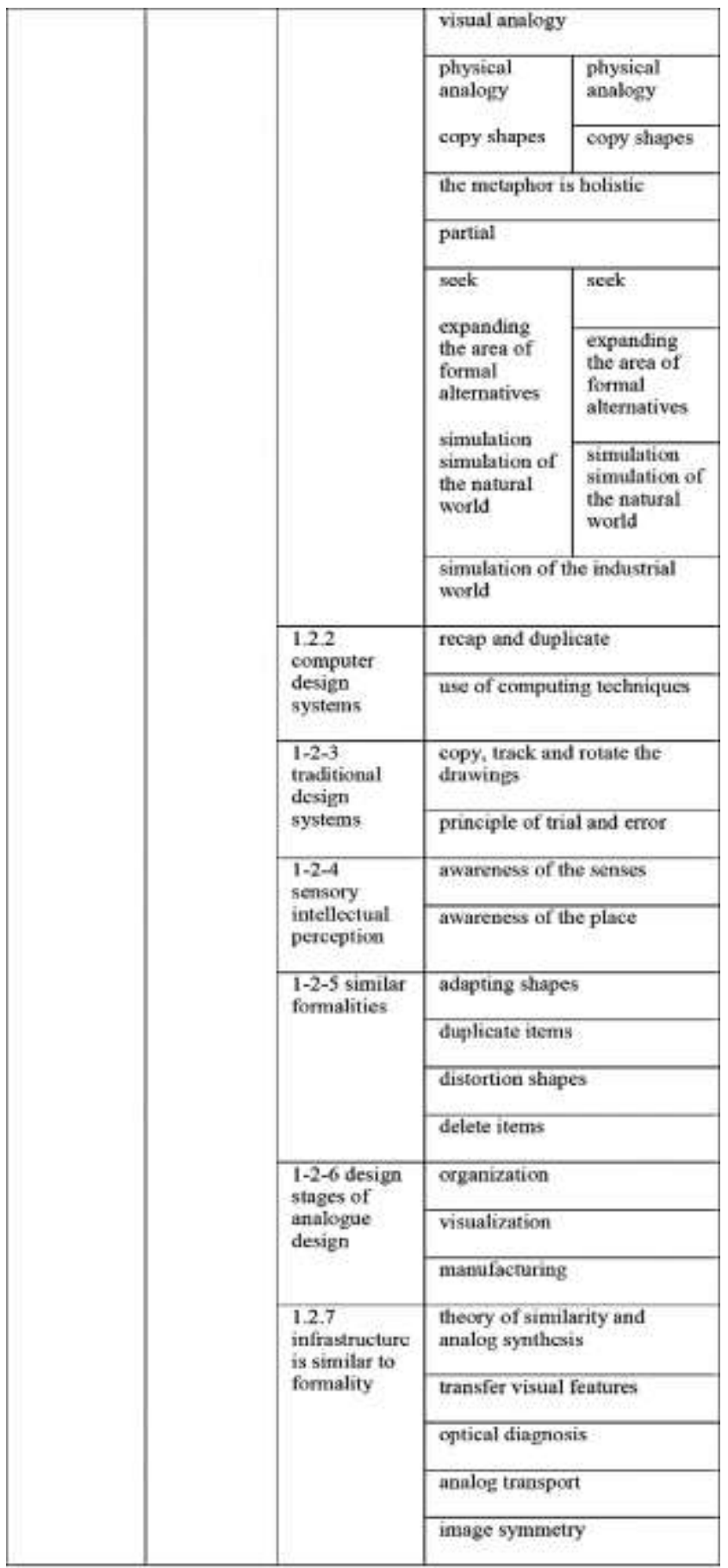




\section{5. practical study:}

After reviewing the knowledge presented to the strategy of analogue thinking based on thought and drawing the comprehensive theoretical framework of the strategy and defining its vocabulary, the basic requirements for the application of the practical study, which represents the second stage of the solution of the research problem, which include the selection of the vocabulary of application and the formulation of hypotheses, To select the methods of measuring the variables and the method of measurement, to apply the vocabulary of the frame to the selected samples and to analyze the data. It is applied to a set of samples chosen for the reasons The comprehensiveness of the vocabulary and its relation to the process of design and the creation of architectural products, the impact of these a variable directly on the architectural products, most studies took those a variable as a source for the creation of architectural products, containing these a variable on the values and indicators detailed to ensure the ease of measurement and accuracy. The hypotheses of research are represented by [analogic thinking is a fundamental and analogy part of a strategy, the multiple analogies that support the same result make the argument stronger, the more analogy the object becomes. The more powerful the products is, the more analogy] .

Table 3 shows the description of Case studies:

\begin{tabular}{|l|r|l|}
\hline \multirow{3}{*}{} & $\begin{array}{r}\text { Sample } \\
\text { code }\end{array}$ & The project / China Tower \\
\cline { 2 - 3 } & $\mathbf{a}$ & Designer / IMB \\
\cline { 2 - 3 } & \multicolumn{3}{|c|}{ Site / China } \\
\hline & \multicolumn{2}{|c|}{ Definition of description } \\
\hline
\end{tabular}

Tower Bank of China [abbreviated BOC Tower] is one of the most exclusive skyscrapers in Hong Kong. The building was tallest in Hong Kong and Asia from 1989 to 1992, and was the first building outside the United States breaking the 305 meter barrier [1,000 feet] [37] The structure adopted in the design of this building is analogy to the bamboo shoots, which symbolize the means of living and prosperity in terms of analogy with plants, not form, but the idea of construction to form the building. What distinguishes forms of nature simulation phenomenon of growth with stability and change to adapt to the environment and represent them in the presence of different formations The appearance and existence of a fixed and balanced relationship is critical, since the truncation of part of the plant may not affect it, and the fractured parts have the ability to grow and not disturb the system. The analogy used is analogy to the intellectual composition using the simulation mechanism of the natural world and symbolizes For the sample with the symbol a

\begin{tabular}{|l|l|l|}
\hline \multirow{2}{*}{$\begin{array}{l}\text { code } \\
\text { cample }\end{array}$} & $\begin{array}{l}\text { The project / City of Arts and } \\
\text { Sciences }\end{array}$ \\
\cline { 2 - 3 } & Designer / Felix Candela \\
\hline & $\mathrm{b}$ & Site / Spain \\
\hline & Definition of description \\
\hline
\end{tabular}

The city of the arts and sciences in Valencia or Valencia in Spain, specifically on the banks of the river Toria or can be said in the course of the river itself caused severe floods changed the course of the river in 1957, and was exploited the rest of the area to build this dazzling city, Arts and sciences by the end of 1994 to 2004, and then continued to build until the city now covers an area of 350 thousand $\mathrm{km}$ for the engineers Santiago Calatrava, Felix Candela [9, p. 3], the most important buildings are [eye knowledge] The glass building, if you look at it will give you the first glance that it was appointed The idea that the composition of what is designed well and suitable for its purpose will be absolutely beautiful through its suitability. That purpose, with its expressive, symbolic and aesthetic aspects and values, the idea was similar to that of man. Man is a social being that includes society and society. He is the one who brings about the reconstruction of the land. From ancient times until today, man is a source of similarity and consideration of man. On its body and members, but extends to the understanding of the laws inherent in it as an object with a physical body and devices and modes of 3D, [29, p2-3] and will symbolize the sample with the symbol b.

\begin{tabular}{|c|c|c|}
\hline \multirow{4}{*}{$1 / 1 / 10$} & \multirow[t]{2}{*}{ Sample code } & The project / Kauffman Center \\
\hline & & Designer / Safdie Architects \\
\hline & c & Site / Kansas City \\
\hline & \multicolumn{2}{|r|}{ cription } \\
\hline
\end{tabular}

There is a pair of shell-like shapes containing two halls for the Performing Arts Center in Kansas by architect Moshe Safdie of Safdie Architecture. The Kaufmann Center is made up of stainless steel plates. The idea of the project is taken from the sound engineering as it is not taken from the shape The sound waves are transmitted through the material and the form of sound waves in acoustic physics, where the wave is spread in liquids and gases as a longitudinal wave and it is also in the air, for example, the sound spreads in the air in such a way that the pressure of the air periodically, And so on. Therefore, the idea of similarity with the method of transmission of sound waves and in line with the nature of the project was used as a formality analogy by the use of similar mechanisms intellectually and formally depending on the sources of intellectual similarities and the idea of strings in the construction of the structure where the effect of the idea is observed at the level Formal, functional and structural, and will symbolize the sample with the symbol c [30].

\section{Method of Measurement:}

This section specifies the method of measuring the set of variables at the levels related to the theoretical framework, The method of measuring the analytical descriptive measurement method is based on the direct reference to the table according to the selected samples based on the,do not check it if the values are recorded on the table of variables.

The data are analyzed in this case by calculating the percentage of each variable according to the formula of statistical thinking (model of thinking): The intellectual model $=($ variable value $/$ sum of variables $) * 100$

\section{$\mathbf{M i}=[\mathbf{x i} / \text { sum xi] }]^{* 100}$}

The variable can be a key in the analogue thinking method depending on the number of signals obtained and which determines the value of the percentage if it refers to:

when getting a [3-6] signal any ratio $50 \%-100$ or It is secondary when it gets [0-3] any signal ratio $0 \%-49 \%$.

The measurement form for the application of samples can be explained according to the vocabulary of the theoretical theoretical framework, as shown in Table 4:

Table 4. Shows the analysis of the results

\begin{tabular}{|c|c|c|c|c|c|}
\hline $\begin{array}{c}\text { The } \\
\text { Main } \\
\text { variable }\end{array}$ & $\begin{array}{c}\text { Secondary } \\
\text { variable }\end{array}$ & $\begin{array}{l}\text { The sub- } \\
\text { variable }\end{array}$ & $\frac{\text { sample }}{\underline{c}}$ & $\frac{\text { sample }}{\underline{\mathbf{a}}}$ & $\frac{\text { sample }}{\underline{\mathbf{b}}}$ \\
\hline \multirow{12}{*}{1} & \multirow{5}{*}{$1-1$} & $1-1-1$ & $\bullet$ & 0 & $\bullet$ \\
\hline & & 1-1-2 & $\bullet$ & $\bullet$ & 0 \\
\hline & & $1-1-3$ & $\bullet$ & $\bullet$ & $\bullet$ \\
\hline & & 1-1-4 & $\circ$ & $\bullet$ & 0 \\
\hline & & $1-1-5$ & $\bullet$ & $\bullet$ & $\bullet$ \\
\hline & \multirow{7}{*}{$1-2$} & $1-2-1$ & 0 & 0 & 0 \\
\hline & & $1-2-2$ & - & 0 & 0 \\
\hline & & $1-2-3$ & $\bullet$ & $\bullet$ & $\circ$ \\
\hline & & $1-2-4$ & $\bullet$ & $\bullet$ & $\circ$ \\
\hline & & $1-2-5$ & $\bullet$ & 0 & 0 \\
\hline & & $1-2-6$ & $\bullet$ & 0 & 0 \\
\hline & & $1-2-7$ & $\bullet$ & $\bullet$ & $\bullet$ \\
\hline
\end{tabular}




\subsection{Discussion of Results:}

After applying the theoretical framework and measuring the variables in all the selected projects, the results of the application and verification of the hypotheses of the research will be discussed. In light of the objectives of the study and the hypotheses presented, the results will be analyzed:

The mechanisms of employing analogue thinking: It refers to the set of mechanisms and methods used to achieve similarity by thinking, followed by designers to analyze and solve design problems and rates of achievement of these mechanisms are shown in table 5. :

Table 5. Shows the analysis of the results

\begin{tabular}{|c|c|c|c|c|c|c|}
\hline 巳 & 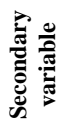 & 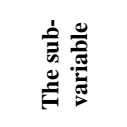 & 영 & 영유 & 윻ㅂ & 绨 \\
\hline \multirow{14}{*}{$\underline{1}$} & \multirow{6}{*}{$\underline{1-1}$} & 1-1-1 & $\bullet$ & $\circ$ & $\bullet$ & $83 \%$ \\
\hline & & $1-1-2$ & $\bullet$ & $\bullet$ & 0 & $66 \%$ \\
\hline & & 1-1-3 & $\bullet$ & $\bullet$ & $\bullet$ & $100 \%$ \\
\hline & & $1-1-4$ & 0 & $\bullet$ & 0 & $16.6 \%$ \\
\hline & & $1-1-5$ & $\bullet$ & $\bullet$ & $\bullet$ & $100 \%$ \\
\hline & & $\begin{array}{c}\text { Percentage } \\
\text { achieve }\end{array}$ & $83 \%$ & $66 \%$ & $50 \%$ & \\
\hline & \multirow{8}{*}{$\underline{1-2}$} & $1-2-1$ & 0 & 0 & 0 & $33.3 \%$ \\
\hline & & $1-2-2$ & $\bullet$ & $\circ$ & 0 & $\% 66$ \\
\hline & & $1-2-3$ & $\bullet$ & $\bullet$ & 0 & $50 \%$ \\
\hline & & $1-2-4$ & $\bullet$ & $\bullet$ & 0 & $50 \%$ \\
\hline & & $1-2-5$ & $\bullet$ & o & $\bullet$ & $50 \%$ \\
\hline & & $1-2-6$ & $\bullet$ & $\circ$ & 0 & $33 \%$ \\
\hline & & $1-2-7$ & $\bullet$ & $\circ$ & $\bullet$ & $50 \%$ \\
\hline & & $\begin{array}{l}\text { Percentage } \\
\text { achieved }\end{array}$ & $\underline{85.7 \%}$ & $\underline{42.8 \%}$ & $14.2 \%$ & \\
\hline
\end{tabular}

It is noted that the index of the secondary variable, the mechanisms of conceptual intellectual systems, is achieved in the samples by $65 \%$. The secondary variable achieved by the systems of formal physical systems is achieved in the samples by $42.8 \%$, so $65 \%$ And greater than 5 is positive, so it is observed from the logical equation products that the mechanisms of the intellectual systems of the same represent a fundamental part in the achievement of similarity as a strategy in which analogue thinking is achieved by searching for ideas of solutions and relying mainly on the variables [the mechanisms of analogue thinking, The design process In order to achieve the greatest possible number of similarities and thus achieve intellectual similarity. It is noted that sample B is more widely used and used for analogue devices using intellectual analogue thinking mechanisms. This satisfies the hypothesis that [analogue thinking is an integral part of a similar strategy, The same result makes the argument stronger. The more similar objects are achieved, the more powerful and creative the products is. The more similar [the two] the stronger the counterpart.

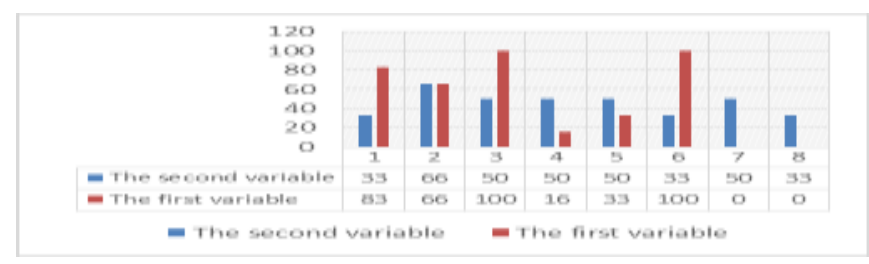

Figure 2. Shows how much each variable is achieved according to the first variable (the mechanisms of employing analogue thinking as a strategy / (source researcher
The mechanics of physical systems are based on a set of visual systems that use metaphor, transcription, simulation and visual analogy to organize and visualize the stages of analogue design. As they work on the transmission and diagnosis of visual features, the mechanisms of similar intellectual systems are an essential part of achieving analogy as a strategy by searching for New solutions from previous ideas and their adoption mainly on the variables intellectual mechanisms that connect the thought of symmetry with the variables of the design process, and this satisfies the hypothesis that analogue thinking is a fundamental and the same as a strategy.

\section{Conclusions:}

1. The analogy is a strategy to solve the Design problem and a way of scientific thinking It draws the similarities and differences between the source and the goal to transfer a particular solution or issue from the source to the target, and calls for Analogyical reasoning of the three main target in different percentages [solve problems, explain to others, identify problems] The analogy is a linguistic phenomenon, a form of speech to refer two things that are not literally analogy through symbolism and abstraction. They are analogy as a method or means of comparison between analogy and differentiated characteristics of objects and their purpose is to find a reasonable link to far-reaching ideas by associating them with ideas Mentally close to the purpose of forming new relationships between the things attentive to the creative side, analogy means a comparison between analogy and differentiated characteristics of objects and their purpose is to find a reasonable link to far-reaching ideas by associating them with ideas that are close to the mind in order to form new relationships between things as they perform a comparative and comparative work.

2. Theoretically correlates theoretically with multiple concepts either in partial or complementary form with the concept or conceptual structure, which indicates diversity in the change of the location of the analogy to other concepts according to the situation and this is in line with the strategic nature of the concept The design using the same as the creator of the creative product depends on the source First refer to the symmetry of any source use of a previous example in another field or a prior knowledge to solve the new problem.

3. The use of analogy on the creation of multi-dependence on the recipient as a way to create associations between historical and modern images and according to their relationships and their links, both stereotyped and formal, impose imposed public frameworks role in symmetry.

4. Architectural thought is an important medium in achieving analogy features that ensure the continuity of architecture over time. These features are at the level of all or part of the Perception analogy flexibility and the force of stripping the previous positions and restructuring the design within the same scope to achieve the performance of real action and interactive architecture, To reach creativity and uniqueness in the formulation of architecture, Analogy thinking is a paradigm shift in the thinking curriculum if it is able to simplify the design process and solve architectural problems by using the previous knowledge to reach the best solutions

5. The concept of Analogyical reasoning refers to several mechanisms that are used to explain a principle or idea and related to the relations between logic, knowledge and retrieval based on structural characteristics of a common structural structure that lead to the diversity and enrichment of semantic levels of architectural products. 
6. Analogy thinking is important and necessary in the creative processes to produce a design work that leads to real action at the level of perception and innovation is related to the people and their mental memory in the mind as it grows the identity of the architectural products is according to intellectual conditions include the behavior of Architect and architecture, on the other hand, Place, age, upper patterns, theoretical and intellectual synchronization in life

7. Note that man deals with architecture intellectually before the process of production in practice and within two dimensions the first dimension derived from nature starting from the environmental and structural systems and materials available in any virtual environment and the second dimension consists of extracting the values and meanings of this and linked to its activity and products This dimension to the mental system and the nature of mental perception, which deals with the person is aware of the external environment, , the personal environment, and notes that the thought leads to the continuity of civilization as the same person with his ideas and previous experiences to interact spatially with his environment and time Between the old and the old .. between the accident and the expected .. So the permanence of the occurrence of great importance in the impact and impact on the community and the recipient of ideas affect the different aspects of the architectural process

8. The Analogyical reasoning contains a set of mechanisms to employ it through the reliance on intellectual mechanisms [conceptual, functional], which are based on the system of integrating and matching the architectural ideas implicitly and philosophically and the intellectual borrowing from the previous knowledge in a compatible or opposite way according to the type of analogy required in the architectural products, The Analogy system comprises a set of relational s systems that act as a source for deriving the intellectual knowledge in the continuous or continuous sequence of a causal relationship to solve the design problem.

9. Analogy thinking is a set of thought mechanisms that are linked to the same through the use of visual imagination, visualization, implicit metaphor, retrieval and intellectual transfer to form a function of the intellectual design process that works to observe, interpret and retrieve from the cognitive memory by taking into account the variables of the functional and behavioral intellectual design process within the structural system Integrated work to restore intellectual attitudes, functional, formal and customary.

\section{Recommendations:}

- The importance of applying models that lead to Analogyical reasoning, most of which were achieved in buildings from different parts of the developed world, which have become among us years of progress that should be shortened so as to keep up with development and achieve the desired future of Iraqi architecture.

- Attention to the study of Analogyical reasoning and its applications and knowledge in the brain and interact with them to suit the local reality and transform the architect from the attention to the formal aspect only to think about the deep aspects of the design through which interaction with the recipient.

- The establishment of specialized training courses for architects to develop their ability to consider the depth of design and to take advantage of the enormous possibilities and data of Analogyical reasoning to achieve uniqueness in architecture.

- Directing architectural scientific research to study and analyze all mechanisms related to Analogyical reasoning to generate new entries for the design process

- Encourage Iraqi architects to put forward their ideas and expectations for the future of architecture and not to close the thinking and try to find alternatives that may stem from the environment and the local reality itself.

\section{REFERENCES}

[1] Ibraheem, Abdel-Sattar, Creativity and its Applications, Dar Al-Arabi for Publishing and Distribution, Cairo, 1999.

[2] Ibn Manzoor, Article M the L, Beirut Publishing House, Lebanon, 1968.

[3] Ibn Manzoor, The Arab Sanctuary, The American Printing Press, Cairo, Bulaq edition, 1986.

[4] Bitar, Sawsan, Philosophy, Sociology and Beliefs, vol. IX, Beirut, 2014

[5] Al-Tahnawi, Muhammad Ali Scouts of the Arts and Sciences Conventions, Waqf Library of Books, 1996.

[6] Al-Jabri, Structure of the Arab Mind, Publishing Center for Arab Unity Studies, 2010.

[7] Durat Ismail, The Book of Thinking in Architecture, A Novel Risk, published book, 2013.

[8] Abdel Rahman, Taha, in the Origins of Dialogue and Renewal of Speech Science, The Arab Cultural Center, 2, 2000

[9] Safo, Baida, analogy in the process of architectural design in the academic center, published research, University of Mosul, 2008.

[10] Tayye, Ahmed, The Mechanism of Thinking Like [Study in Visualization], 2010-Article, http://www.ebnkhaldoun.com/auteur.php?article=220.

[11] Abdul Muttalib, Mamdouh, Development of Thinking Skills - Dar AlQalam Books, Egypt, 2016.

[12] Al-Attiyah, Marwan, Dictionary of meanings, 2012.

[13] Al-Issawi, Hassan Yousef, The analogy and metaphor in architectural design, Studies, Humanities and Social Sciences, vol. 44, no. 2, 2017.

[14] Kurdish, Ahmed al-Sayyed, thinking what? What are its components? What types? Does he have tools? , Article 2002, http://kenanaonline.com/users/ahmedkordy/posts/321287.

[15] AlSayed - Ahmad Kurdi - Analysis of the theory of needs - article published -2011

[16] An outline of English phonetics-Daniel Jones- W Heffer Sons LTD Cambridge Enhlend 9Th 1972] ‘p217

[17] Baker R., Designing the future: the computer transformation of reality, Thames and Hudson, Hong Kong, 1993.

[18] Cameron McEwan, Architecture of Analogy, Notes on Andrew Melville Hall as a transitional work in the architecture of James Stirling, 2014.

[19] Clement, C. A., \& Centner, D, Systematicity as a selection constrai in analogyical mapping. Proceedings of the Tenth Annual Conference of the Cognitive Science Society, Montreal,1988

[20] Daniel Jones, An outline of English phonetics, W Heffer Sons LTD Cambridge Enhlend 9Th, 1972

[21] Flew A., A Dictionary of Philosophy, Pan Books, Macmillan Press, Laurence Urdang Associates Ltd. , Great Britain,1979

[22] Gentner D., ' Analogyical Reasoning, Psychology of ', northwestern university, Evanston, Illinois, USA,2011.

[23] Gentner D. , Bowdle B. , Wolff P. , and Boronat C. ,'Metaphor is like Analogy',2001 
[24] Ginty, Tim Mc, "Concepts in Architecture", in Snyder,J. \& Catanese, A.J.'Introduction to Architecture”, Mc Graw- Hill Book Company, 1979.

[25] Ginty-A Design Support System Using Analogy, Artificial Intelligence in Design ,book, pp 7,1979.

[26] Gruber, A biomimetic approach to architecture and design by analogy, , Research publication ,2017.

[27] Hyunmin Cheong ,Understanding Analogyical Reasoning in Biomimetic Design, An Inductive Approach, 2014

[28] Itkonen E, Analogy as Structure and Process: Approaches in Linguistic, Cognitive, John Benjamins publishing company,2005

[29] Koca., An appraisal of analogy based design practices in architecture education, , Research publication, 2014

[30] Linsey, fundamental studies in design-by-analogy: a focus on domainknowledge experts and applications to transactional design problems, Research publication,2014.

[31] Mary Lou Maher ,Using analogyical reasoning to design buildings, Research publiction, 2015

[32] Ozgu Ozkan and Fehmi Dogan ,Cognitive strategies of analogyical reasoning in design: Differences between expert and novice designers, Faculty of Architecture, Izmir Institute of Technology, Urla, TR-35430 Izmir, Turkey-2012.

[33] Rowe P. G., Design Thinking, Seventh Edition, MIT press, USA,1988

[34] Broadbent G. , "Architecture in the Future,"Riba Journal, October, London, 1970.

[35] Broadbent. G., Design in architecture [ architecture and the human sciences] London, 1973

[36] Banham, Reyner, Theory and Design in the First Machine Age, New York, Praeger Publishers, 1960.

[37] Bono, and Edward, Lateral Thinking: Creativity Step by Step ,New York ,Harper,1973.

[38] Stafford B. M., Visual Analogy:Consciousness as the Art of Connecting, MI PressT,USA,2001

[39] http://www.3d2ddesign.com/more_architecture.php?id=39\&design=4

[40] http://www.3d2ddesign.com

[41] https://ar.wikipedia.org/wiki

[42] http://kenanaonline.com/users/ahmedkordy/posts/321287.

[43] http://www.metamia.com/index.php

[44] https://www.biology-online.org

[45] http://www.metamia.com/index.php 